\title{
PRELIMINARY EVIDENGE ON TAKEOVER TARGET RETURNS IN SPAIN: A NOTE
}

\author{
Garlos Ogaña, J. Ignagio Peña and Dolores Robles*
}

\section{INTRODUCTION}

Mergers and takeovers are one of the most researched areas in finance, see Weston et al. (1990). However, most studies concentrate on US markets and, more recently, on UK markets, see for instance Higson and Elliott (1993). But there is still little additional evidence coming from small or emerging markets to complement the results already established for the larger markets. This paper aims to provide that evidence by analyzing a small market i.e. Spain (about $1.1 \%$ of the total world market in 1994) but one that is reaching significant magnitudes relative to most European stock markets.

This is, to the authors' knowledge, the first study of takeovers in Spain based on Spanish stock market data. Before the Stock Market Act (1989) there were few recorded takeovers due to a number of factors, among them, the lack of clear legal regulation on these matters, and the limits on foreign investment in Spain. In fact, the first registered takeover took place in 1983. In the period from 1983 to 1985 there were some takeovers, but a significant amount was only reached after Spain joined the European Community in 1986. In the period from 1986 to 1989 there were about 30 takeovers but many of them suffered problems due to the lack of a regulatory authority. Since the Stock Market Act an increasing number of takeovers has been registered. ${ }^{1}$ However, the number of operations is not comparable with the major markets and therefore, our sample is relatively small. Thus, the results should be viewed as only preliminary evidence on the subject.

One particular aspect of takeover activity is analyzed in this paper, the target share price returns. We find abnormal positive returns for the target firms. In comparison with the well-known results for the US market reported by Keown and Pinkerton (1981), abnormal returns in the Spanish market seem to be bigger. We also found that in the first part of the year before the announcement period, firms that became targets did not show significant

\footnotetext{
* The authors are from Departamento de Economía de la Empresa, Universidad Carlos III de Madrid. They gratefully acknowledge financial support from the Fundacion Banco Bilbao Vizcaya. They are also grateful to Eudald Canadell and Elias Lopez (CNMV) and to Domingo Garcia-Coto (Bolsa de Madrid) who kindly supplied data and to Gonzalo Rubio for useful suggestions. They also acknowledge the helpful comments of two anonymous referees. The usual caveat applies.
}

Address for correspondence: J. Ignacio Peña, Departamento de Economía de la Empresa, Universidad Carlos III de Madrid, Madrid 126, 28903 Getafe (Madrid), Spain. 
abnormal returns, though there was some significant upturn in the two months before the bid. The rest of the paper is organized as follows. The next section presents the data and the third section the methodology. The empirical results are presented in the fourth section and in the final section we address some concluding comments.

\section{DATA}

A total of 120 successful takeovers (OPA) were recorded in the Madrid Stock Market (MSM) during the period 1990 to 1994. The sample includes takeovers of industrial, commercial and financial companies. ${ }^{2}$ About $95 \%$ of the takeovers were friendly (i.e. the first bid was not rejected by the target management). There were 127 bidders $^{3}$ (many bidders were foreign companies whose shares are not traded in Spain) and 120 targets. From that sample, we selected the firms which met the following requirements:

(i) The stock is continuously listed on the MSM for 244 days before the takeover's announcement date, and at least 60 days after.

(ii) The announcement and the outcome date must be officially registered by the Comision Nacional del Mercado de Valores (CNMV), which is the Spanish version of the US's SEG. ${ }^{4}$

(iii) Events which involve the transformation of a public corporation into a privately-held firm (Going Private) are excluded from the sample.

After applying this criteria, our final sample consisted of 71 targets and 32 bidders. It may be said that the degree of statistical confidence one could assume by analyzing bidders is somewhat limited and therefore we concentrate in the analysis of targets in this paper. We analyzed in a previous unpublished paper the (Spanish) bidder's returns using the same methodology we report in this paper. The results suggested that for the period before the announcement date the shareholders of acquiring firms neither gained nor lost statistically significant excess returns. After the merger, we did not find significant evidence of decline in cumulative average excess returns. However, the results should be viewed as merely tentative, because the small sample size makes drawing firm conclusions difficult.

\section{METHODOLOGY}

We follow the standard approach to event studies, developed by Fama et al. (1969), and Brown and Warner (1980 and 1985). Event studies in finance measure stock performance after subtracting a benchmark return based on beta risk. We compute abnormal returns over three periods: (a) the preannouncement period, including 244 days pre-announcement to the day 
before official announcement (when the target's stock trade is suspended), (b) the announcement period, from the day when the target's stock trade is resumed (day 0 ) to the day in which the bid goes unconditional, and (c) the post-takeover period. Periods (b) and (c) must cover at least three months (60 trading days). The reason is that the duration of the announcement period varies across takeovers, but in most cases (almost 90\%) the outcome date is one to three months after the bid announcement. For each of the sample securities, daily rates of return were calculated as:

$$
R_{j t}=\ln \left(P_{j t}+D_{j t}\right)-\ln \left(P_{j t-1}\right)
$$

where $P_{j t}$ is the closing price for security $j$ on day $t$ and $D_{j t}$ is the cash dividend announced formally on day $t$. Note that $t$ is the day when the shares first trade 'ex dividend'. Abnormal returns were estimated by means of the market model:

$$
R_{j t}=\alpha_{j}+\beta_{j} R_{m t}+\epsilon_{j t}
$$

where $R_{m t}$ is the return on IGBM stock index and $\alpha_{j}, \beta_{j}$ are parameters to be estimated and $\epsilon_{j t}$ are random innovations. The estimated abnormal return is given by the following equation

$$
e_{j t}=R_{j t}-\left(a_{j}+b_{j} R_{m t}\right) .
$$

Three methods were used to estimate these parameters. First, ordinary least squares (OLS). Second, the method by Cohen et al. (1983) (CHMSW) with a maximum of five days in price adjustments, which generalizes Scholes and Williams (1977), to take into account frictions in the trading process (nonsynchronous trading, etc.). Third, the Market Adjusted Return method (MAR) which can be thought of as a particular case of OLS, where $\alpha_{j}=0, \beta_{j}=1$ for all firms. Since $\alpha_{j}$, for daily data, is small and the average $\beta_{j}$ over all firms is 1 , this approximation usually produces acceptable results.

To eliminate possible event-driven bias in the estimates of $\alpha_{j}, \beta_{j}$ the parameters were estimated using the three methods (OLS, CHMSW, MAR) over the first 224 trading days of the study, thus excluding the 25 trading days prior to the announcement date. ${ }^{5}$ Then, for these 25 days and for periods (b) and (c) (usually 90 data points in total), we computed average abnormal returns (AAR) over all stocks in day $t$ as follows:

$$
\operatorname{AAR}_{t}=\frac{1}{\mathcal{N}} \sum_{i=1}^{\mathcal{N}} e_{i t}
$$

where $\mathcal{N}$ is the number of securities in the sample with a return in $t$. The cumulative average abnormal return (CAAR) from event day $t_{1}$ to $t_{2}$ is:

$$
\mathrm{CAAR}_{t_{1}}^{t_{2}}=\sum_{t=t_{1}}^{t_{2}} \mathrm{AAR}_{t}
$$


If there are no unusual price movements prior to the announcement date, one would expect both AAR and CAAR to fluctuate randomly. It should be noted however, that CAAR follows a random walk and can easily give the appearance of 'significant' positive or negative drift when none is present. Testing for abnormal returns is performed with four different statistics, two for AAR and two for CAAR. For the AAR we compute the standard $t$-ratio (which is shown as the parallel lines in Figure 1) and $T_{2}$ which is the signs test which counts the number of positive and negative abnormal returns and computes their significance using $z$-statistics which is approximately normally distributed with mean 0 and variance 1 under the null hypothesis.

The statistic is computed using:

$$
\hat{p}=\frac{1}{\mathcal{N}} \sum_{i=1}^{\mathcal{N}} \frac{1}{k} \sum_{t=t_{1}}^{t_{2}} S_{i t}
$$

where $k=t_{2}-t_{1}$ and $S_{i t}$ is an indicator variable, taking value 1 if the AAR is positive and zero otherwise. The statistic is:

$$
T_{2}=\frac{\beta-n \hat{p}}{[n \hat{p}(1-\hat{p})]^{\frac{1}{2}}}
$$

where $\beta$ is the number of positive abnormal returns. For the CAAR we compute $T_{3}$ which is the ratio of the cumulative average abnormal return to its estimated standard deviation:

$$
T_{3}=\frac{\mathrm{CAAR}_{t_{1}}^{t_{2}}}{\left[\sum_{t=t_{1}}^{t_{2}} S^{2}\left(\mathrm{AAR}_{t}\right)\right]^{\frac{1}{2}}}
$$

with autocorrelation adjustments, see Brown and Warner (1985, p. 29), and $T_{4}$ which is the nonparametric test proposed by Corrado (1989). This last procedure involves first transforming each security's time series of abnormal returns into their respective ranks. Let $K_{i t}$ denote the rank of the abnormal return $e_{i t}$ in security $i$ 's time series of abnormal returns:

$$
K_{i t}=\operatorname{rank}\left(e_{i t}\right) \quad t=t_{1}, \ldots t_{2}
$$

where $e_{i t} \geq e_{i j}$ implies $K_{i t} \geq K_{i j}$ and $\left(t_{2}-t_{1}\right) \geq K_{i t} \geq 1$. By construction the average rank is one-half plus half the number of observed returns, or $K^{*}=\left(\left(t_{2}-t_{1}\right) / 2\right)+$ $1 / 2$. The rank statistic substitutes $\left(K_{i t}-K^{*}\right)$ for the abnormal return $e_{i t}$, yielding this day $j$ test statistic:

$$
T_{4}=\frac{1}{\mathcal{N}} \sum_{i=1}^{\mathcal{N}}\left(K_{i j}-K^{*}\right) / S(K)
$$

where the standard deviation $S(K)$ is calculated using the entire $\left(t_{2}-t_{1}\right)$ period: 


$$
S(K)=\sqrt{\frac{1}{t_{2}-t_{1}} \sum_{t=t_{1}}^{t} 2\left[\frac{1}{\mathcal{N}} \sum_{i=1}^{\mathcal{N}}\left(K_{i t}-K^{*}\right)\right]^{2}} .
$$

This rank test is correctly specified no matter how skewed the cross-sectional distribution of abnormal returns.

\section{EMPIRICAL RESULTS}

Daily AAR and CAAR for the whole sample and some selected subsamples were computed using the three methods. To save space we present only the results of OLS estimation because no significant difference was found in the results given by the three methodologies. The results for the MAR and CHMSW methods are available from the authors on request. Test statistics and graphs are given in Table 1 and Figures 1 and 2. In Figure 1 (AAR with asymptotic confidence intervals) the most striking feature is the huge positive residual (about 14\%) in day 0 which is somewhat bigger than the values

Table 1

$T_{2}$-Statistic and Percentage of Positive AAR and Statistics $T_{3}$ and $T_{4}$ for CAAR of Target Companies

\begin{tabular}{lccccc}
\hline Sample & $\%$ AAR $>0$ & $T_{2}$-Statistic & CAAR $(\%)$ & $T_{3}$-Statistic & $T_{4}$-Statistic \\
\hline$(-60,60)$ & 62 & $* * *$ & 41.81 & $* * *$ & $* * *$ \\
$(-40,40)$ & 63 & $* * *$ & 40.03 & $* * *$ & $* * *$ \\
$(-20,20)$ & 70 & $* * *$ & 35.18 & $* * *$ & $* * *$ \\
$(-10,10)$ & 72 & $* * *$ & 22.01 & $* * *$ & $* * *$ \\
$(-5,5)$ & 70 & $* * *$ & 16.72 & $* * *$ & $* * *$ \\
$(-60,0)$ & 62 & $* * *$ & 38.69 & $* * *$ & $* * *$ \\
$(-40,0)$ & 62 & $* * *$ & 35.36 & $* * *$ & $* * *$ \\
$(-20,0)$ & 64 & $* * *$ & 32.34 & $* * *$ & $* * *$ \\
$(-10,0)$ & 59 & $* *$ & 19.62 & $* * *$ & $* * *$ \\
$(-5,0)$ & 60 & $* *$ & 15.31 & $* * *$ & $* * *$ \\
$(0,60)$ & 72 & $* * *$ & 18.18 & $* *$ & $* *$ \\
$(0,40)$ & 70 & $* * *$ & 18.77 & $* *$ & $* *$ \\
$(0,20)$ & 72 & $* * *$ & 16.84 & $* * *$ & $* * *$ \\
$(0,10)$ & 65 & $* * *$ & 16.49 & $* * *$ & $* * *$ \\
$(0,5)$ & 64 & $* * *$ & 15.52 & $* * *$ & $* * *$ \\
\hline
\end{tabular}

Notes:

This table shows the $T_{2}$ (signs test) statistic and the percentage of positive Average Abnormal Residuals (AAR) and the Cumulative Average Abnormal Residuals (CAAR) for targets in Spanish takeovers. Also this table describes the levels of significance of the $T_{3}$ (Brown and Warner, 1985) and $\mathcal{T}_{4}$ (Corrado, 1989) statistics. The AAR and CAAR are computed for various subperiods. The $(-x, 0)$ and $(0, y)$ both contain the announcement day reaction. Statistical significance levels are denoted by $* * * 1 \%$ and $* * 5 \%$. 
Figure 1

Average Abnormal Returns of Target Takeovers

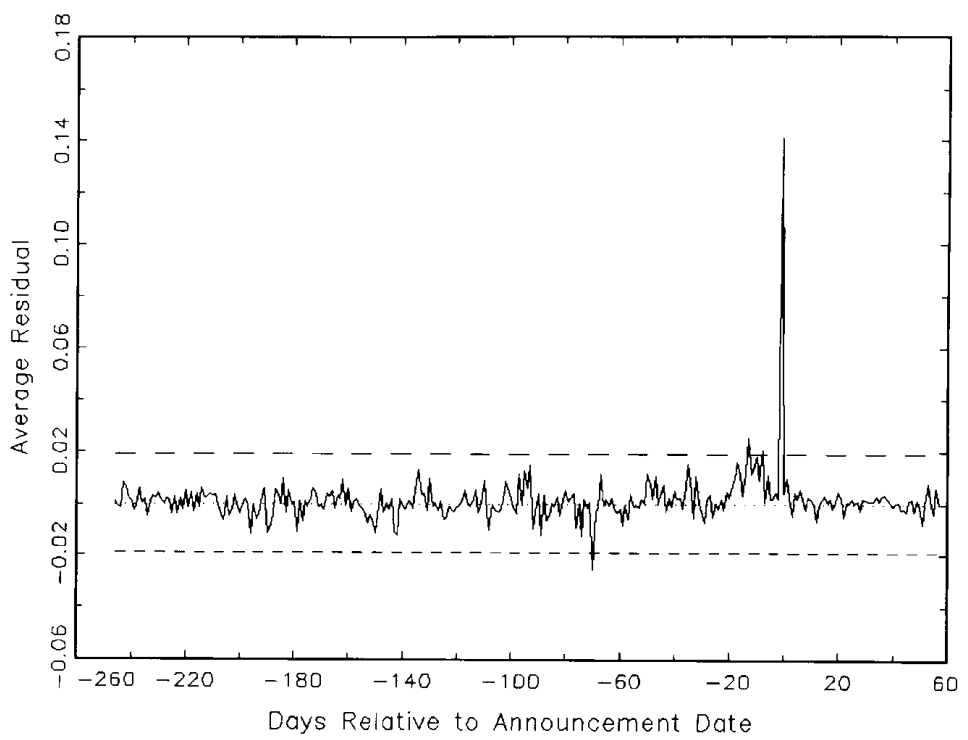

Notes:

This figure shows the Average Abnormal Returns (AAR) for 71 target firms traded in the Spanish Stock Market before and after the Announcement date $(t=0)$. Abnormal returns were calculated using the market model: $R_{j t}=\alpha_{j}+\beta_{j} R_{m t}+\epsilon_{j t}$ where $R_{j t}$ is the return $t$ of stock's target firm $j, R_{m t}$ is the return on IGBM stock index (used as a market return) and $\alpha_{j}, \beta_{j}$ are parameters to be estimated and $\epsilon_{j t}$ are random innovations. The estimated abnormal return $e_{j t}$ is given by the following equation: $e_{j t}=R_{j t}-\left(a_{j}+b_{j} R_{m t}\right)$. The estimated parameters $a_{j}, b_{j}$ are computed using ordinary least squares (OLS). The AAR are computed over all stocks in day $t$ as follows: $\mathrm{AAR}_{t}=(1 / \mathcal{N}) \sum e_{i t}$ where $\mathcal{N}$ is the number of securities in the sample with a return in $t$. The two horizontal lines are the asymptotic confidence intervals for the null hypotheses that AAR are zero.

reported for the US and UK markets (usually lower than 10\%). Also there is a bunch of positive abnormal residuals, some of them nearly significant in the 20 previous trading days before the announcement date. This might suggest information leakage before the announcement date. In Figure 2 we may observe an apparently random behaviour in the first days. However, around day -30 there seems to be a change and CAAR takes on abnormal characteristics, rising quickly.

In summary, about $41 \%$ positive abnormal return goes to target shareholders in our sample of successful tender offers. More than one-third of this amount is earned before the announcement date. Thus, it may be said that targets in our sample earn substantial premiums. This is consistent with the 


\section{Figure 2}

\section{Cumulative Average Abnormal Returns of Target Takeovers}

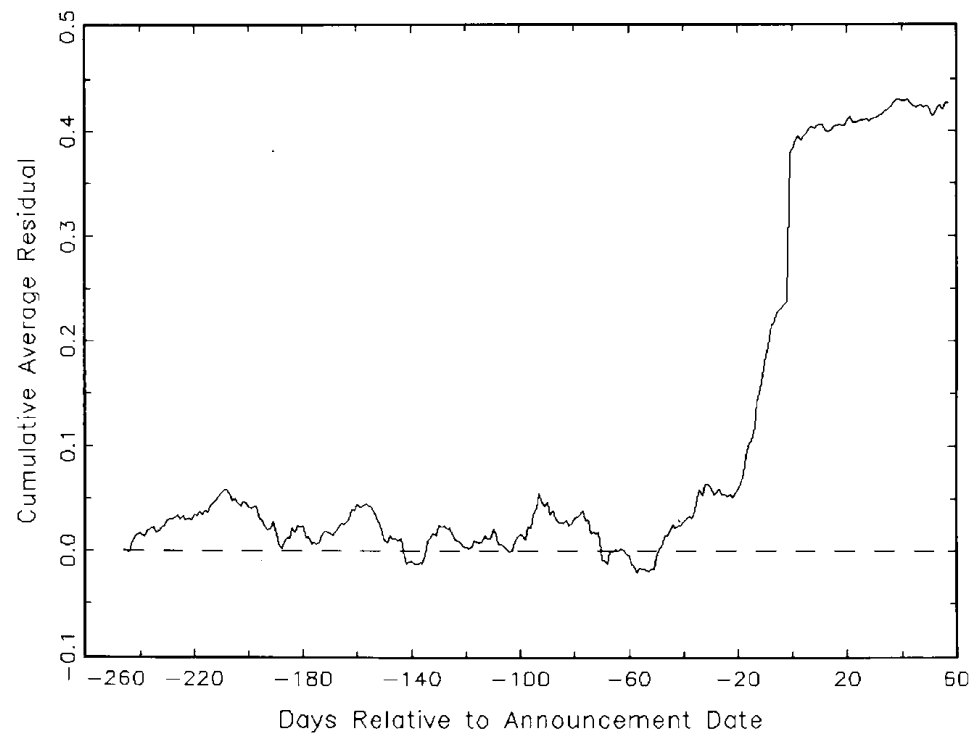

Notes:

This figure shows the Cumulative Average Abnormal Returns (CAAR) for 71 target firms traded in the Spanish Stock Market before and after the Announcement date $(t=0)$. Abnormal returns were calculated using the market model: $R_{j t}=\alpha_{j}+\beta_{j} R_{m t}+\epsilon_{j t}$ where $R_{j t}$ is the return $t$ of stock's target firm $j, R_{m t}$ is the return on IGBM stock index (used as a market return) and $\alpha_{j}, \beta_{j}$ are parameters to be estimated and $\epsilon_{j t}$ are random innovations. The estimated abnormal return $e_{j t}$ is given by the following equation: $e_{j t}=R_{j t}-\left(a_{j}+b_{j} R_{m t}\right)$. The estimated parameters $a_{j}, b_{j}$ are computed using ordinary least squares (OLS). The AAR are computed over all stocks in day $t$ as follows: $\mathrm{AAR}_{t}=(1 / \mathcal{N}) \sum e_{i t}$ where $\mathcal{N}$ is the number of securities in the sample with a return in $t$. The Cumulative Average Abnormal Returns (CAAR) from event day $t_{1}$ to $t_{2}$ is computed as follows:

$$
\mathrm{CAAR}_{t_{1}}^{t_{2}}=\sum_{t=t_{1}}^{t_{2}} \mathrm{AAR}_{t} .
$$

available evidence on the US and UK markets. ${ }^{6}$

\section{CONCLUDING REMARKS}

The empirical evidence presented in this note suggests that the behaviour of 
stock prices during takeovers in a small market (Spain) is quite similar to the pattern observed in the larger US and UK stock markets. Specifically, we have found that target shareholders gain significant abnormal returns in the announcement period. In the first part of the year before the announcement period, firms that become targets do not show significant abnormal returns, though there is some significant upturn in the two months before the bid.

While these findings are relevant for the particular market considered, it is still too early to conclude that small stock markets share the characteristics of large ones. First, there are few studies of small markets. Second, merger activity during the period considered results, at least in part, from a particular institutional change, namely the opening of the Spanish economy to the EU's common market. And third, recent new Spanish legislation on takeovers may be changing the financial environment in which such activity is taking place.

\section{NOTES}

1 From 1990 to 1994 the number of registered takeovers was 120. On average, the total amount of resources involved was about $2 \%$ of total market value each year. The peak was reached in 1991 when the resources involved amounted to more than $4 \%$ of the total market value of that year.

2 It is interesting to note that, in our sample, typically the bidder's market value was about $200 \%$ of the market value of the average firm in the Indice General de la Bolsa de Madrid (IGBM). This is a value-weighted index that is made up by the 72 main firms listed in the MSM and is used in this study as a 'market factor'. The target's value was about $50 \%$ of the average firm in the IGBM. This result suggests that acquired firms are smaller and is in agreement with many published studies, see Morck et al. (1987).

3 The number of bidders is greater than the number of targets because in some cases there is a joint offer from a group of companies. For instance when CAMPSA was the target, the OPA was jointly managed by five different firms: PETRONOR, REPSOL, CEPSA, ERTOIL and PETROMED.

4 The takeover procedure is as follows. The bid must be presented in the CNMV which sets the announcement date and automatically stops the target's stock trade. If the bid is accepted by all parts (CNMV, bidder and target) target's stock trade is resumed and an outcome date is fixed. The outcome date is the date on which the offer becomes unconditional.

5 A check of the stability of $\beta_{j}$ (estimated by OLS) between the first 112 and last 112 trading days of this 224 trading day sample indicated the $\beta_{j}$ 's were stable over this period.

6 In our sample, the bidder is domestic in 32 firms and foreign in 39 . We computed separately the AAR and CAAR in both cases. We found slightly higher abnormal returns when the bidder is domestic but the difference with the abnormal returns in the whole sample is not statistically significant at usual levels.

\section{REFERENCES}

Brown, S. and J.B. Warner (1980), 'Measuring Security Price Performance', Fournal of Financial Economics, Vol. 8, pp. 205-58.

(1985), 'Using Daily Stock Returns: The Case of Event Studies', Journal of Financial Economics, Vol. 14, pp. 3-31.

Cohen, K.J., G.A. Hawawini, S.F. Maier, R.A. Schwartz and D.K. Whitcomb (1983), 'Friction in the Trading Process and the Estimation of Systematic Risk', Journal of Financial Economics, 
Vol. 12, pp. 263-78.

Corrado, C.J. (1989), 'A Nonparametric Test for Abnormal Security-price Performance in Event Studies, Fournal of Financial Economics, Vol. 7, pp. 197-226.

Fama, E.F., L. Fisher, M.C. Jensen and R. Roll (1969), 'The Adjustment of Stock Prices to New Information', International Economic Review, Vol.10, pp. 1-21.

Higson, C. and J. Elliott (1993), 'The Returns to Takeovers. The UK Evidence'. IFA Working Paper 173-93 (London Business School).

Keown, A.J. and J.M. Pinkerton (1981), 'Merger Announcements and Insider Trading Activity: An Empirical Investigation', Journal of Finance, Vol. 36, pp. 855-69.

Morck, R., A. Shleifer and R.W. Vishny (1987), 'Characteristics of Targets of Hostile and Friendly Takeovers', in A.J. Auerbach (ed.), Corporate Takeovers: Causes and Consequences.

Weston, J.F., K. S. Chung and S.E. Hoag (1990), Mergers, Restructuring and Corporate Control (Prentice-Hall). 